\title{
Original $\mid$ PATTERNS OF TREATMENT FAILURE, PROGNOSTIC FACTORS AND Article SURVIVAL IN LOCOREGIONALLY HEAD AND NECK CANCER PATIENTS
}

\author{
Hanan Gamal-Eldin Mostafa, Samir Shehata Eid, Samia Abd Elkarim, Salwa Fathy \\ Mohamed
}

Department of Clinical Oncology, Faculty of Medicine and Radiotherapy, South Egypt Cancer Institute, Assiut University, Assiut, Egypt

\begin{abstract}
Patient Methods: Two hundred and thirty previously untreated patients with head and neck squamous cell carcinoma (HNSCC) were followed up. The following parameters were studied: age, sex, clinical $\mathrm{T}$ and $\mathrm{N}$ stage, histology grade and anatomic site of the tumor, smoking status and performance. Photon energy, radiation dose, and treatment duration were also recorded. For the postoperative patients, the surgical margin status, number of positive and excised nodes, and tumor size were recorded. Each patient underwent a physical examination, complete blood count, serum chemical profile, chest radiography, dental evaluation, and a full endoscopic examination. Computed tomography of the site of the primary tumor and the neck was done. During treatment, patients were examined at least weekly. Once treatment ended, an evaluation was required at 9 weeks then every two months for the first year, every 6 months for the next two years.

Results: The tumor response, and treatment-related adverse effects were assessed at baseline, and at each follow-up assessment.

The number of HNSCC cases within the period of study was 230 with a relative frequency $10 \%$ to all malignancies. The median age of our patients was 54 years with male to female ratio of 5.5 to 1 , and according to the Karnofsky performance status $4.4 \%$ of patients had KPS of $60 \%$. The number of cases with grade II tumor differentiation was significantly higher than those with grade I or grade III $(\mathrm{p}<0.001)$. Patients who had no further disease during follow up were significantly higher among the group with tumor margin free after surgery. Patients who had loco regional recurrence were significantly higher among the group with tumor margin not free after surgery, while no significant difference was found between the to groups regarding distant metastasis. Of the 90 patients who underwent surgery, the surgery of 50 cases had been complete. In 40 patients, tumor excision was incomplete. Analysis of different prognostic factors in this study showed that stage, and hemoglobin level have a significant impact on the disease-free and the overall survival.
\end{abstract}

Key Words: Chemoradiotherapy, head and neck cancer, patterns failure, prognostic factors, tumor margin.

Corresponding Author: Hanan Gamal-Eldin Mostafa, Clinical Oncology Department, Faculty of Medicine, Assiut University. Assiut University Hospital, Tel.: 088 2323972, +20 0104082002,

Fax: 088-2333327 (Assiut University Hospital), E-mail: han91mostafa@yahoo.com

\section{INTRODUCTION}

Head and neck cancer represents about $17 \%$ of all malignant tumors in Egypt ${ }^{1}$. Worldwide, it represents the $6^{\text {th }}$ most prevalent cancer. Regarding prognosis, head and neck cancers are classified into favorable and unfavorable sites, with great varieties in 5 year survival rates. The best chance for the cure of a patient with head and neck cancer is his first radical treatment attempt. This is explained by the fact that recurrent head and neck cancer after surgery and/or radiotherapy are poorly salvaged due to the postoperative and postradiation fibrosis. These recurrent head and neck cancers carry an unfavorable outcome and prognosis ${ }^{2}$. Addition of systemic therapy to the standard radiotherapy has 2 theoretical aims. First, to increase locoregional control and second to decrease systemic dissemination. In this regard, several radiotherapy and chemotherapy combinations have been tried to improve the poor survival of patients with bulky primary tumors or with massive lymphadenpathy. ${ }^{3}$

This study was designed to analyze patterns of failure and prognostic factors for locoregional and distant recurrences, progression-free survival and overall survival using 2 different treatment strategies in patients with head and neck cancer. The relation between the histologically determined status of surgical margins and the cause of treatment failure was studied in a sample of surgically treated head and neck cancer patients. The role concurrent cisplatin and radiotherapy in reducing the probability of locoregional failure and distant metastasis compared to radiotherapy alone was assessed among locally advanced cases not amenable for surgery. 


\section{PATIENTS AND METHODS}

Two hundred and thirty previously untreated patients with head and neck squamous cell carcinoma (HNSCC) were followed up. All were patients presenting to the South Egypt Cancer Institute during the period from January, 2001 to January, 2003. The following parameters were studied: age, sex, clinical T \& N stage, histology grade and anatomic site of the tumor, smoking status and performance. Photon energy, radiation dose, and treatment duration were also recorded. For the postoperative patients, the surgical margin status, number of positive and excised nodes, and tumor size (as the product of the two maximum diameters) were recorded. Each patient underwent physical examination, complete blood count, serum chemical profile, chest radiography, dental evaluation, and a full endoscopic examination. Computed tomography of the site of the primary tumor and the neck was done.

\section{Treatment modalities ${ }^{4}$ :}

Patients with T1/T2 were treated by surgery or radical radiotherapy. For larger tumors, surgery was the first option, and radiotherapy was used when the morbidity associated with surgery was estimated too high.

Patients who underwent primary surgery with curative intent: They were divided into 2 groups. The first group was formed by those with normal epithelial linings at their surgical margins. The second group consisted of those with dysplasia of any grade at the margin and those with incomplete tumor excision.

Incomplete tumor excision meant presence of invasive tumor at the margin or the distance between individual tumor nests being greater than the distance between the resection margin and the tumor nest closest to this margin.

\section{Patients who received radiotherapy were classified into:}

- Postoperative adjuvant radiotherapy,

- Radical radiotherapy,

- Or combined with chemotherapy.

Patients received postoperative radiotherapy consisting of conventionally fractionated doses of 2Gy each in 5 weekly sessions. Maximal and minimal targetvolume doses and the maximal dose to the spinal cord were recorded. Treatment was conducted on linear accelerators of $6 \mathrm{MV}$ with the use of isocenteric techniques. A large volume encompassing the primary site and all draining lymph nodes at risk received a dose of up to 54 Gy in 27 fractions over a period of 5.5 weeks. Regions that were at high risk for malignant dissemination or inadequate resection margins received a 12-Gy boost (total, 66 Gy) in 33 fractions over a period of 6.5 weeks. The dose to the spinal cord was limited to 45Gy.

Patients who received definitive radiotherapy alone were treated with external-beam megavoltage irradiation to a total planned dose of $70 \mathrm{~Gy}$. Chemotherapy consisted of $20 \mathrm{mg}$ of cisplatin $/ \mathrm{m}^{2}$ of body-surface area once weekly during the course of radiotherapy. All received prophylactic antiemetic agents.

\section{Follow up:}

During treatment, patients were examined at least weekly. Once treatment ended, an evaluation was required at 9 weeks then every two months for the first year, every 6 months for the next two years. The tumor response, and treatment-related adverse effects were assessed at baseline, and at each follow-up assessment.

\section{Study end-points:}

The primary end point was local and regional tumor control; failure was defined as the reappearance of tumor in the original tumor bed or the development of cervicalnode metastases after treatment.

Secondary end points were disease-free survival, over-all survival, and adverse effects. Disease-free survival was measured from the time of randomization to the time of discovery of the first evidence after treatment of any tumor (local, regional, metastatic, or second primary). Overall survival was measured from the date of randomization to the date of death from any cause.

Treatment-related adverse effects were scored according to the WHO Common Toxicity Criteria. Treatment- related adverse effects ${ }^{5}$ were categorized as acute (occurring within 90 days after the start of radiotherapy) or late (continuing or occurring after 90 days).

\section{Statistical methods:}

The survival functions were calculated for the twoyear disease free and overall survival according to the Kaplan \& Meier method ${ }^{6}$. The comparison between the survival curves of the different groups was performed using log-rank statistics ${ }^{7}$. Chi-square test was used to compare the distribution of frequencies among various groups.

\section{RESULTS}

The total number of adult cancer cases presented to the South Egypt Cancer Institute during the period of study was 2291 cases. The number of HNSCC cases within this period was 230 with a relative frequency $10 \%$ to all malignancies. 
Table (1) shows patients clinical characteristics, Karnofsky performance status and primary site of the tumor. The median age of our patients was 54 years with male to female ratio of 5.5 to 1 , and according to the Karnofsky performance status $4.4 \%$ of patients had KPS of $60 \%$.

Table 1: Patient Characteristics.

\begin{tabular}{lcc}
\hline Characteristic & $\begin{array}{c}\text { No. of patients } \\
\text { (total 230) }\end{array}$ & $\begin{array}{c}\% \\
\text { (total 100\%) }\end{array}$ \\
& & \\
\hline Sex: & $188(42)$ & $81.7(18.3)$ \\
M (F) & & \\
Age: & $107(123)$ & $46.5(53.5)$ \\
<60 (>60) & & \\
Clinical presentation: & 51 & 22 \\
Mass & 92 & 40 \\
Hoarseness of voice & 80 & 35 \\
Dysphagia & 7 & 3 \\
Visual disturbances & & \\
KPS: & 10 & 4.4 \\
60\% & 18 & 34.3 \\
70\% & 79 & 53.5 \\
80\% & 123 & \\
90\% & & 21.3 \\
Primary site: & 48 & 3.9 \\
Oral cavity & 9 & 11.7 \\
Nasopharynx & 59 & \\
Oropharynx & 87 & \\
Larynx & 27 & \\
Hypopharynx & & \\
\hline
\end{tabular}

Table (2) shows patient classification regarding T\&N staging, tumor differentiation and treatment modality. The number of cases with grade II tumor differentiation was significantly higher than those with grade I or grade III $(\mathrm{p}<0.001)$.

Table 2: Patient Classification Regarding $\mathrm{T}$ and N Staging, Tumor Differentiation and Treatment Modality.

\begin{tabular}{lcc}
\hline & No. of patients (total 230) & \% \\
\hline T stage & 23 & \\
T1 & 41 & 10 \\
T2 & 81 & 18 \\
T3 & 85 & 35 \\
T4 & & 37 \\
N stage & 112 & \\
N0 & 44 & 48.7 \\
N1 & 38 & 19.1 \\
N2 & 36 & 16.5 \\
N3 & & 15.7 \\
Tumor Differentiation & 69 & \\
Grade I & 115 & 30 \\
Grade II & 46 & 50 \\
Grade III & & 20 \\
Treatment Modality & 50 & \\
Surgery & 40 & 22 \\
Surgery + Radiotherapy & 60 & 17 \\
Radiotherapy & 80 & 26 \\
Radiochemotherapy & & 35 \\
&
\end{tabular}

Table (3) Follow up results of the surgical group. Patients who had no further disease during follow up were significantly higher among the group with tumor margin free after surgery. Patients who had locoregional recurrence were significantly higher among the group with tumor margin not free after surgery, while no significant difference was found between the to groups regarding distant metastasis.

Table 3: Follow up Results of the Surgical Group.

\begin{tabular}{lccc}
\hline $\begin{array}{l}\text { Follow-up } \\
\text { data }\end{array}$ & $\begin{array}{c}\text { Tumor-margin } \\
\text { free } \\
\text { No. (\%) }\end{array}$ & $\begin{array}{c}\text { Tumor-margin } \\
\text { not free } \\
\text { No. (\%) }\end{array}$ & $\begin{array}{c}\text { Significance } \\
\mathbf{P}<\end{array}$ \\
\hline $\begin{array}{l}\text { No further } \\
\text { disease }\end{array}$ & $38(76)$ & $16(40)$ & 0.01 \\
$\begin{array}{l}\text { Locoregional } \\
\text { recurrence }\end{array}$ & $5(10)$ & $14(35)$ & 0.01 \\
$\begin{array}{l}\text { Distant } \\
\text { metastases }\end{array}$ & $7(14)$ & $10(25)$ & NS \\
Total & $50(100)$ & $40(100)$ & \\
\hline
\end{tabular}

Out of the 90 patients who underwent surgery, the surgery of 50 cases had been complete. In 40 patients, tumor excision was incomplete conforming to the definition as given before.

Table (4) shows response to radiotherapy and radiochemotherapy.

Table 4: Response to Radiotherapy and Radiochemotherapy.

\begin{tabular}{lccccc}
\hline $\begin{array}{l}\text { Treatment } \\
\text { Response }\end{array}$ & \multicolumn{2}{c}{$\begin{array}{c}\text { Radiotherapy } \\
\text { (60 cases) }\end{array}$} & \multicolumn{3}{c}{$\begin{array}{c}\text { Radiochemotherapy } \\
\text { (80 cases) }\end{array}$} \\
\cline { 2 - 6 } & No. & $\mathbf{\%}$ & No. & $\mathbf{\%}$ & $\begin{array}{c}\text { Significance } \\
\mathbf{( P < )}\end{array}$ \\
\hline $\begin{array}{l}\text { Complete } \\
\text { response }\end{array}$ & 15 & 25 & 40 & 50 & 0.001 \\
$\begin{array}{l}\text { Partial } \\
\text { response }\end{array}$ & 27 & 45 & 24 & 30 & NS \\
$\begin{array}{l}\text { Stable } \\
\text { disease }\end{array}$ & 6 & 10 & 4 & 5 & NS \\
$\begin{array}{l}\text { Progressive } \\
\text { disease }\end{array}$ & 12 & 20 & 12 & 15 & NS \\
\hline
\end{tabular}

Tables (5-8) and figures (1-3) show relation of the studied variables to response and prognosis.

Table 5: Relation between Response and T-Stage Among Patients Receiving Radiotherapy.

\begin{tabular}{lcccccccc}
\hline T-Stage & \multicolumn{2}{c}{ CR } & \multicolumn{2}{c}{ PR } & \multicolumn{2}{c}{ SD } & \multicolumn{2}{c}{ PD } \\
& No. & $\%$ & No. & $\%$ & No. & $\%$ & No. & $\%$ \\
\hline T1 & 6 & 100 & & & & & & \\
T2 & 9 & 90 & 1 & 10 & & & & \\
T3 & & & 17 & 68 & 2 & 9.5 & 6 & 28.6 \\
T4 & & 9 & 45 & 4 & 17.4 & 6 & 26.1 \\
P value & 0.008 & 0.007 & 0.003 & 0.05 \\
\hline
\end{tabular}

$\mathrm{CR}=$ Complete response, $\mathrm{PR}=$ Partial response, $\mathrm{SD}$ stable disease, $\mathrm{PD}$ $=$ Progressive disease. 
Table 6: Relation between Response and T-Stage among Patients Receiving Radiochemotherapy.

\begin{tabular}{lcccccccc}
\hline T-Stage & \multicolumn{2}{c}{ CR } & \multicolumn{2}{c}{ PR } & \multicolumn{2}{c}{ SD } & \multicolumn{2}{c}{ PD } \\
& No & $\%$ & No & $\%$ & No & $\%$ & No & $\%$ \\
\hline T1 & & & & & & & & \\
T2 & & & 1 & 6.25 & & & & \\
T3 & 22 & 55 & 14 & 38.5 & 2 & 5 & 2 & 2 \\
T4 & 18 & 15 & 10 & 43.3 & 2 & 5 & 10 & 25 \\
P value & & & & & & & 0.089 \\
\hline
\end{tabular}

$\mathrm{CR}=$ Complete response, $\mathrm{PR}=$ Partial response, $\mathrm{SD}=$ Stable disease, $\mathrm{PD}=$ Progressive disease

Table 7: Significant Prognostic Factors for Disease Free Survival.

\begin{tabular}{lcc}
\hline $\begin{array}{l}\text { Significant } \\
\text { Prognostic factor }\end{array}$ & $\begin{array}{c}\text { Radiotherapy } \\
\text { Group No of } \\
\text { patients with disease } \\
\text { free survival (\%) }\end{array}$ & $\begin{array}{c}\text { Chemoradiotherapy } \\
\text { Group No of } \\
\text { patients with disease } \\
\text { free survival (\%) }\end{array}$ \\
\hline $\begin{array}{c}\text { Hemoglobin Level } \\
\text { Anemic patients }\end{array}$ & $7(33.3 \%)$ & $10(35.7 \%)$ \\
Normal patients & $18(46.2 \%)$ & $26(50 \%)$ \\
Significance & $\mathrm{P}<0.001$ & $\mathrm{P}<0.001$ \\
T-Stage & $25(93 \%)$ & $27(96.4 \%)$ \\
T1 - T3 & $26(74.3 \%)$ & $41(74.5 \%)$ \\
T4 & $\mathrm{P}<0.04$ & $\mathrm{P}<0.03$ \\
Significance & &
\end{tabular}

Table 8: Significant Prognostic Factors for Overall Survival.

\begin{tabular}{lcc}
\hline $\begin{array}{l}\text { Significant } \\
\text { Prognostic factor }\end{array}$ & $\begin{array}{c}\text { Radiotherapy } \\
\text { Group No. of } \\
\text { patients with disease } \\
\text { free survival (\%) }\end{array}$ & $\begin{array}{c}\text { Chemoradiotherapy } \\
\text { Group No. of } \\
\text { patients with disease } \\
\text { free survival (\%) }\end{array}$ \\
\hline Hemoglobin Level & & \\
Anemic patients & $8(38 \%)$ & $10(35.7 \%)$ \\
Normal patients & $18(46.2 \%)$ & $26(50 \%)$ \\
Significance & $\mathrm{P}<0.001$ & $\mathrm{P}<0.001$ \\
T-Stage & & \\
N0- N1 & $33(94.3 \%)$ & $27(96.4 \%)$ \\
N2- N3 & $25(73.5 \%)$ & $30(75.5 \%)$ \\
Significance & $\mathrm{P}<0.04$ & $\mathrm{P}<0.04$ \\
\hline
\end{tabular}

2-Year Acturtal Loc al Control

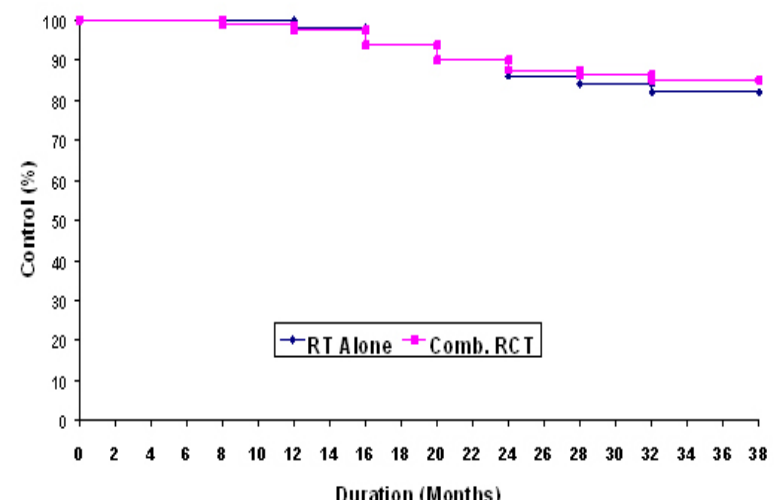

Fig. 1: Two-Year Actuarial Local Control Rate for RT Alone and RCT.
2-Year Disease Free Survival

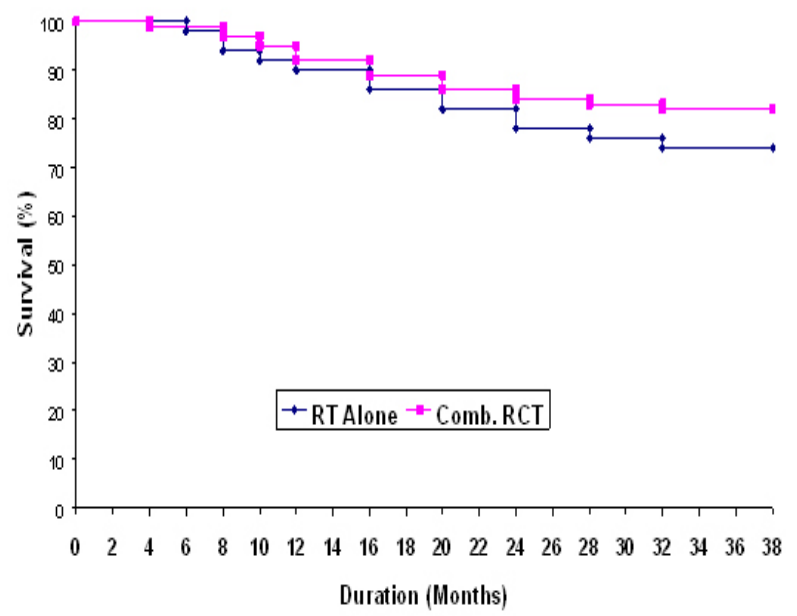

Fig. 2: Two-Year Disease-Free Survival for RT Alone and RCT

\section{2-Year Overall Survival}

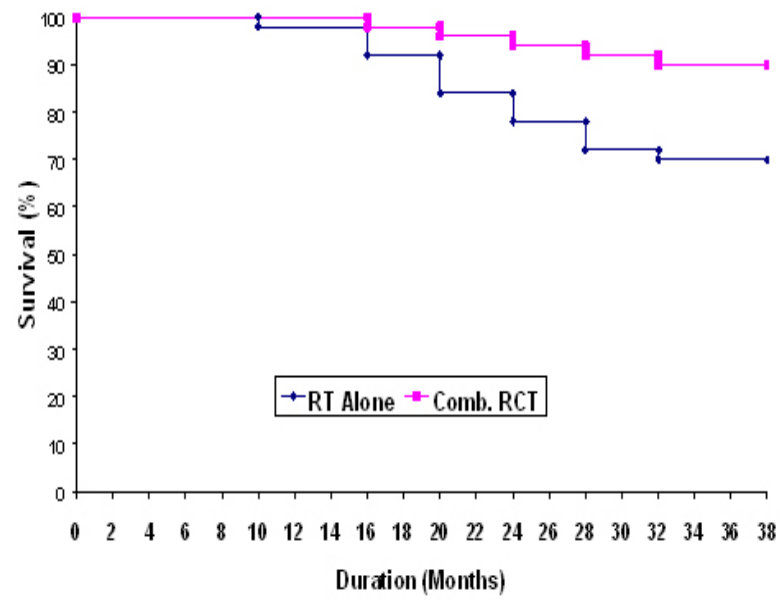

Fig. 3: Two Year Overall Survival for RT Alone and RCT.

No statistically significant relation could be detected between response and age, sex, Karnofsky performance status, pathological grading of the tumor and N-stage of the tumor. Table (9) shows treatment related toxicity in the studied groups of patients. 
Table 9: Treatment-Related (grade 3) Toxicity.

\begin{tabular}{|c|c|c|c|}
\hline Adverse Effect & Radiotherapy (No. of Patients) Total 60 & Chemoradiotherapy (No. of Patients) Total 80 & Significance \\
\hline \multicolumn{4}{|l|}{ Acute Effects } \\
\hline Leucopenia & 2 & 8 & \\
\hline Anemia & 2 & 7 & \\
\hline Thrombocytopenia & - & 2 & \\
\hline Nausea and Vomiting & - & 18 & $\mathrm{P}<0.01$ \\
\hline Diarrhea & - & 5 & \\
\hline Mucositis & 16 & 20 & \\
\hline Total & 20 & 60 & $\mathrm{P}<0.001$ \\
\hline \multicolumn{4}{|l|}{ Late Effects } \\
\hline Dysphagia & 6 & 9 & \\
\hline Xerostomia & 2 & 5 & \\
\hline Hoarseness of Voice & 2 & 2 & \\
\hline Total & 10 & 16 & NS \\
\hline
\end{tabular}

\section{DISCUSSION}

It was found that the median age of our patients is 54 years with male to female ratio of 5.5 to 1 . This is in agreement with Copper et al. ${ }^{8}$ who found that the median age of their patients was 55 years wi6th male to female ratio of $6: 1$.

The number of cases with grade II tumor differentiation was significantly higher than those with grade I or grade III. This is in agreement with Fortin et al. ${ }^{9}$ who found that grade II HNSCC is the most common histological grade.

Most of the patients presented with locally advanced tumor 166 cases representing $72 \%, 37 \%$ of them were T4 and the remaining 35\% were $\mathrm{T} 3 . \mathrm{T} 1$ and $\mathrm{T} 2$ participated by $10 \%$ and $18 \%$, respectively. This is in agreement with Lee et al. ${ }^{10}$ and Bernier et al. ${ }^{2}$ who stated that head and neck cancer commonly presented as locally advanced disease.

Patients who had no further disease were significantly higher among the group who was surgically managed with tumor-margin free than in the group surgically managed with tumor-margin not free. Locoregional recurrence was significantly lower in the tumor-margin free group than in the tumor-margin not free group, while there was no significant difference between the two groups regarding distant metastases (Table 3). This is in agreement with Slootweg et al. ${ }^{11}$ who demonstrated comparable results. The occurrence of further disease, locoregional recurrence and distant metastasis in the group surgically managed with tumor-margin free could be explained by the fact that residual cancer cells might remain undetected in the surgical margin by the pathologist [minimal residual cancer $]^{12}$. Another explanation was suggested that tumorrelated mucosal precursor lesions, "fields" of genetically altered cells, may be left behind, and these might give rise to new invasive carcinomas. ${ }^{13}$

The number of cases who achieved complete response in the group of patients who received combined radiochemotherapy was significantly higher than in the group who received radiotherapy alone (Table 4). This is in agreement with Merlano et al. and Hehr et al. ${ }^{3,14}$ who stated that addition of systemic therapy to the standard radiotherapy could improve the poor survival of patients with bulky primary tumors or with massive lymphadenpathy.

T-stage had significantly affected prognosis in patients receiving radiotherapy alone or radiochemotherapy and the disease free survival (Tables 5-7). This is in agreement with Mendenhall et al. ${ }^{15}$ who stated that the most important parameter that has an impact on tumor response after treatment is $\mathrm{T}$ stage.

For the patients received radiotherapy only and those received the combined radiochemotherapy, the 2-year actuarial estimate of disease-free survival was significantly improved ( $74 \%$ vs. $82 \%$ ), and so was the overall survival (70\% vs. 90\%) (Figures 1-3). Merlano et al. ${ }^{14}$ found in their trial that the 5 year disease-free survival was $41 \%$ and $85 \%$, however the 5 -year survival was estimated to be $10 \%$ for the patients received RT alone and $24 \%$ for those received the combined RCT. The difference between the results of this study and those of their trial may be due to longer period of followup with a median of 60 months. Analysis of different prognostic factors in this study (Tables 7-8) showed that stage, and hemoglobin level have a significant impact on the disease-free survival and the over-all survival. This is in agreement with Lee et al. ${ }^{10}$

Acute adverse effects occurred in a significantly higher percentage frequency in the group of patients who received combined therapy than in the group who received radiotherapy alone. The incidence of late adverse effects did not differ significantly between the groups (Table 9). This is in agreement with those results of Cooper et al. which showed similar results. ${ }^{16}$ 


\section{REFERENCES}

1. El Bolkainy MN. Head and neck cancer. In: El Bolkainy MN, editor. Topographic pathology of cancer. 2nd ed. : National Cancer Institute, Cairo University; 2000. p. 7-18.

2. Bernier J, Domenge C, Ozsahin M, Matuszewska K, Lefebvre JL, Greiner RH, et al. Postoperative irradiation with or without concomitant chemotherapy for locally advanced head and neck cancer. N.Engl.J.Med. 2004 May 6;350(19):1945-52.

3. Hehr T, Classen J, Belka C, Welz S, Schafer J, Koitschev A, et al. Reirradiation alternating with docetaxel and cisplatin in inoperable recurrence of head-and-neck cancer: A prospective phase I/II trial. Int.J.Radiat.Oncol.Biol.Phys. 2005 Apr 1;61(5):1423-31.

4. Schantz SP, Harrison LB, Forastire AA. Tumors of the nasal cavity and paranasal sinuses, nasopharynx, oral cavity and oropharynx. In: DeVita VT, Jr., Hellman S, Rosenberg SA, editors. Cancer: Principles and practice of oncology. Philadelphia PA: Lippincott Williams and Wilkins; 2001. p. 797-860.

5. World Health Organization. Handbook for reporting results of cancer treatment. 1979;48.

6. Kaplan EL, Meier P. Nonparametric estimation from incomplete observations. J.Am.Stat.Assoc. 1958;53:467-81

7. Mantel N. Evaluation of survival data and two new rank order statistics arising in its consideration. Cancer Chemother.Rep. 1966 Mar;50(3):163-70

8. Cooper JS, Pajak TF, Forastiere AA, Jacobs J, Campbell BH, Saxman SB, et al. Postoperative concurrent radiotherapy and chemotherapy for high-risk squamous-cell carcinoma of the head and neck. N.Engl.J.Med. 2004 May 6;350(19):1937-44.

9. Fortin A, Couture C, Doucet R, Albert M, Allard J, Tetu B. Does histologic grade have a role in the management of head and neck cancers J.Clin.Oncol. 2001 Nov 1;19(21):4107-16.
10. Lee WR, Berkey B, Marcial V, Fu KK, Cooper JS, Vikram B, et al. Anemia is associated with decreased survival and increased locoregional failure in patients with locally advanced head and neck carcinoma: A secondary analysis of RTOG 85-27. Int. J.Radiat.Oncol.Biol.Phys. 1998 Dec 1;42(5):1069-75.

11. Slootweg PJ, Hordijk GJ, Schade Y, van Es RJ, Koole R. Treatment failure and margin status in head and neck cancer. A critical view on the potential value of molecular pathology. Oral Oncol. 2002 Jul;38(5):500-3.

12. Van Houten VM, Leemans CR, Kummer JA, Dijkstra J, Kuik DJ, van den Brekel MW, et al. Molecular diagnosis of surgical margins and local recurrence in head and neck cancer patients: A prospective study. Clin.Cancer Res. 2004 Jun 1;10(11):3614-20.

13. Van Houten VM, Tabor MP, van den Brekel MW, Kummer JA, Denkers F, Dijkstra J, et al. Mutated p53 as a molecular marker for the diagnosis of head and neck cancer. J.Pathol. 2002 Dec;198(4):476-86.

14. Merlano M, Benasso M, Corvo R, Rosso R, Vitale V, Blengio $\mathrm{F}$, et al. Five-year update of a randomized trial of alternating radiotherapy and chemotherapy compared with radiotherapy alone in treatment of unresectable squamous cell carcinoma of the head and neck. J.Natl.Cancer Inst. 1996 May 1;88(9):583-9.

15. Mendenhall WM, Morris CG, Amdur RJ, Hinerman RW, Mancuso AA. Parameters that predict local control after definitive radiotherapy for squamous cell carcinoma of the head and neck. Head Neck 2003 Jul;25(7):535-42.

16. Cooper JS, Pajak TF, Forastiere AA. Patterns of failure for resected advanced head and neck cancer treated by concurrent chemotherapy and radiation therapy: An analysis of RTOG 9501/Intergroup phase III trial. Int.J.Radiat.Oncol.Biol.Phys. 2002;54(Suppl. 1):2. 
